\title{
A NOTE ON THE DIFFERENTIAL EQUATIONS OF GLEICK-LORENZ
}

\author{
MORRIS W. HIRSCH
}

(Communicated by Kenneth R. Meyer)

\begin{abstract}
It is shown that for the Gleick-Lorenz equations, every solution in the positive octant blows up.
\end{abstract}

We consider the nonlinear system of differential equations

$$
\begin{array}{ll}
\dot{x}_{1}=10\left(x_{2}-x_{1}\right) & =F_{1}(x) \\
\dot{x}_{2}=x_{1} x_{3}+28 x_{1}-x_{2} & =F_{2}(x) \\
\dot{x}_{3}=x_{1} x_{2}-(8 / 3) x_{3} & =F_{3}(x)
\end{array}
$$

for $x=\left(x_{1}, x_{2}, x_{3}\right)$ in the positive orthant $\mathbf{R}_{+}^{3}$, attributed to E. N. Lorenz by J. Gleick [Gleick 1987, p. 323]. Although Gleick describes their dynamics as chaotic [Gleick 1987, p. 30], in a simulation by C. Deno [Deno 1988] the forward orbit of any point other than the origin blows up. We rigorously verify this dynamic behavior.

For vectors $u, f$ we write $u>v$ in case $u_{i}>v_{i}$ for all $i$.

The system is cooperative in $\mathbf{R}_{+}^{3}$, i.e. $\partial F_{i} / \partial x_{j} \geq 0$ for $i \neq j$. Therefore the Müller-Kamke theorem on differential inequalities implies that if $x(t)$ and $y(t)$ are solutions with $x(0)>y(0) \geq 0$ then $x(t)>y(t)$ for all $t \geq 0$ at which both solutions are defined [Müller 1926, Kamke 1932; or see Coppel 1965].

It is easily verified that for any solution $x(t)$ with $x(0)>0$, there is a solution $y(t)$ such that $x(0)>y(0)>0$ and $F(y(0))>0$. It follows from the theory of cooperative systems that each $y_{i}(t)$ is strictly increasing for $t \geq 0$ [Selgrade 1980]. Since there are no equilibria except the origin, $y(t)$ cannot converge; therefore some $y_{i}(t) \rightarrow \infty$ and $\|y(t)\| \rightarrow \infty$. The Müller-Kamke theorem now implies $\|x(t)\| \rightarrow \infty$.

For any solution $z(t)$ with $z(0) \geq 0, z \neq 0$ it is easily seen that $z(t)>0$ for all $t>0$, and the preceding argument shows that $\|z(t)\| \rightarrow \infty$.

It should be noted that these equations differ from those of [Lorenz 1963] in the sign of the term $x_{1} x_{3}$.

Received by the editors April 24, 1988.

1980 Mathematics Subject Classification (1985 Revision). Primary 34C11, 58F13. 


\section{REFERENCES}

[Coppel 1965] W. A. Coppel, Stability and asymptotic behavior of differential equations, Heath, Boston, 1965.

[Deno 1988] C. Deno, University of California at Berkeley, unpublished.

[Gleick 1987] J. Gleick, Chaos, Viking, New York, 1987.

[Kamke 1932] E. Kamke, Zur Theorie der systeme gewöhnlicher differential Gleichungen II, Acta. Math. 58 (1932), 57-85.

[Lorenz 1963] E. N. Lorenz, Determinisitc chaotic flow, J. Atmos. Sci. 20 (1963), 1320-141.

[Müller 1926] M. Müller, Über das Fundamentaltheorem in der theorie der gewöhnlichen differentialgleichungen, Math. Z. 26 (1926), 619-645.

[Selgrade 1980] J. Selgrade, Asymptotic behavior of solutions to single loop positive feedback systems, J. Differential Equations 38 (1980), 80-103.

Department of Mathematics, University of California, Berkeley, California 94720 